\title{
Analysis of Equilibria of a Recurrent Neural Network involving Transcendental Function
}

\author{
Neeraj Sahu \\ Research scholar \\ Department of Mathematics \\ S.M.S Government Science \\ College Gwalior (M.P),India
}

\author{
A.K.Verma \\ Department of Mathematical, \\ Sciences and Computer \\ Applications, Bundelkhand \\ University \\ Jhansi (U.P), India,
}

\begin{abstract}
In this paper we present four node recurrent neural networks system with three weight parameters. This closed recurrent neural network generates a limit cycle. In this system for which the equation of equilibria involves transcendental function tan $\mathrm{h}(\mathrm{X})$ and its iterates. The network is shown to trains a desired periodic signal by varying weights.
\end{abstract}

\section{Keywords}

Neural network, limit cycle, nonlinear dynamics, learning systems, transcendental function, and equilibrium.

\section{INTRODUCTION}

The focus of research in neural network has been shifted to produce more complicated network since Hopfield [5], presented a simplified network. Hale [4] described the attribute of periodic solution which arises through Hopf bifurcation in delay system, Hesting [7] has shown that oscillation behavior of some cellular system have the structure of engineering application knows as recurrent neural network. A. Ruiz, David $\mathrm{H}$. Owens [1] defined a particular class of three node of recurrent neural network which is able to learn and train independently a specific time varying periodic signal.

The motivation for exploring recurrent neural network is their capacity to reach a solution that satisfies many constant McClelland [6] for example in vision system which eases an analysis of an image which optimal satisfies a complex set of disagreeing constant. Marr and Poggio [3] and Rszeliski [8], describe a system which relaxes to find a carriage for a robot satisfying many criteria. Bo. Gao, and Weinian. Zhang, [2] has studied the Equilibria and their bifurcation in a recurrent neural network involving iterates of a transcendental function.

Recently Yingguo Li [9] describe the nonlinear dynamical behavior of three dimensional recurrent neural network with time delay as bifurcation and shows that the Hoff bifurcation occurs when the delay pusses though a sequence of critical values. Yujiao Huang and his co-authors [10] has worked on the dynamical stability analysis of multiple equilibrium points in recurrent neural networks for piecewise linear non decreasing activation functions.

We develop a neural network that understand and duplicate a class of time dependent periodic signals, here we use a gradient descent algorithm to change a parameter of the network so that it modifies itself to learn particular periodic signal.

In the section (ii) we introduced four node recurrent neural networks linearized at the origin, we find the condition for the system to generate a limit cycle. Section (iii) explore the zeros of the system (1)-(4) and the some condition on W1,W2,W3 is derived for uniqueness. In section (iv) we trained the network by using gradient descent algorithm.

\section{Section -II}

In this figure, $\mathrm{U}(\mathrm{t})$ is the input and $\mathrm{Y}(\mathrm{t})$ is the output of the neural network. This recurrent neural network described of the system of nonlinear differential equations

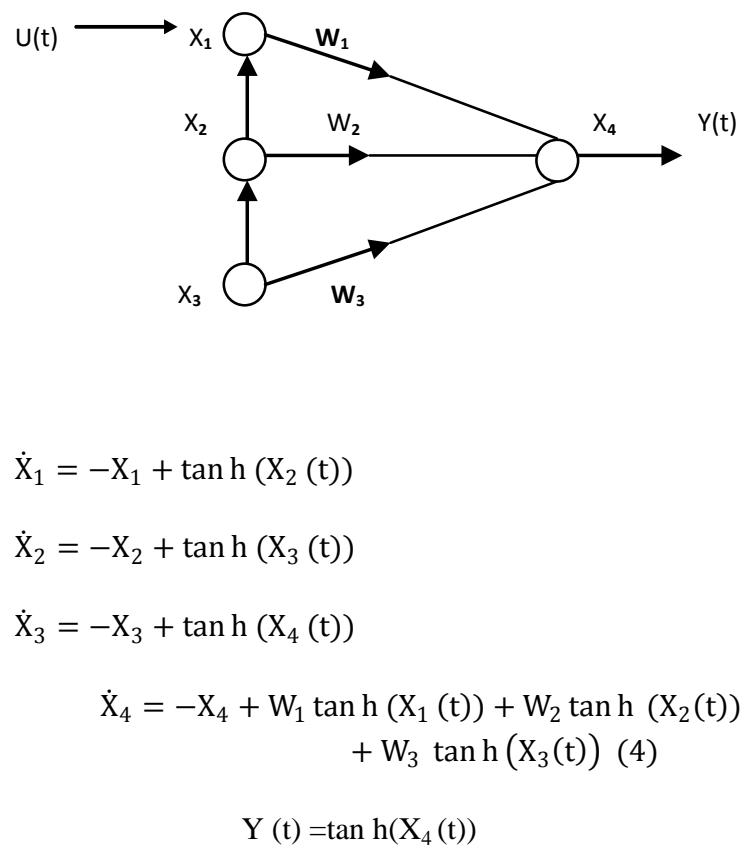

Where $\mathrm{X}(\mathrm{t}) \in \mathrm{Rn}$ is the state $\mathrm{Wi} \in \mathrm{R}, \mathrm{i}=1,2,3$ are the network parameter of weights, $U(t)$ is the input and $Y(t)$ is the output. Linearization at $\mathrm{X}=0$ we find two pair of complex conjugate poles with positive real pole and one negative real pole, then this is a particular type of instability of the equilibrium. At $X=0$ combined with boundedness of the solution forces the system to generate a limit cycle.

The freedom in choosing W1, W2 and W3 in the system (1)-(4) allows us to determine the position of the pole of linearized system and so influences the amplitude and frequency of the corresponding limit cycle.

The linearization of (1)-(4) at $X=0$ given by 


$$
\begin{aligned}
& \dot{\mathrm{z}}_{1}=-\mathrm{z}_{1}+\mathrm{z}_{2} \\
& \dot{\mathrm{z}}_{2}=-\mathrm{z}_{2}+\mathrm{z}_{3} \\
& \dot{\mathrm{z}}_{3}=-\mathrm{z}_{3}+\mathrm{z}_{4} \\
& \quad \dot{\mathrm{z}}_{4}=-\mathrm{z}_{4}+\mathrm{W}_{1} \mathrm{z}_{1}+\mathrm{W}_{2} \mathrm{z}_{2}+\mathrm{W}_{3} \mathrm{z}_{3}
\end{aligned}
$$

If

$$
\begin{aligned}
A & =\left[\begin{array}{lccr}
-1 & 1 & 0 & 0 \\
0 & -1 & 1 & 0 \\
0 & 0 & -1 & 1 \\
\mathrm{~W}_{1} & \mathrm{~W}_{2} & \mathrm{~W}_{3} & -1
\end{array}\right] \\
& =\left[\begin{array}{lccr}
0 & 1 & 0 & 0 \\
-1 & -1 & 1 & 0 \\
0 & 0 & -1 & 1 \\
\mathrm{~W}_{1}+\mathrm{W}_{2} & \mathrm{~W}_{2} & \mathrm{~W}_{3} & -1
\end{array}\right] \\
& =\left[\begin{array}{lcc}
-1 & 1 & 0 \\
0 & -1 & 1 \\
\mathrm{~W}_{1}+\mathrm{W}_{2} & \mathrm{~W}_{3} & -1
\end{array}\right]
\end{aligned}
$$

The roots of the characteristic polynomial A $-\lambda \mathrm{I}=0$ is define by

$$
(-1-\lambda)^{3}+(1+\lambda) \mathrm{W}_{3}-\left(\mathrm{W}_{1}+\mathrm{W}_{2}\right)=0 .
$$

Let

$$
f(\lambda):=-\left[1+\lambda^{3}+3 \lambda^{2}+3 \lambda\right]+(1+\lambda)\left(W_{3}\right)-\left(W_{1}+W_{2}\right)=0 .
$$

Differentiating (5)

$f^{\prime}(\lambda):=3 \lambda^{2}+6 \lambda-\left(W_{3}-3\right)=0$.

The roots of (6) are given by

$\lambda_{1}=-1+\frac{1}{\sqrt{3}} \sqrt{\mathrm{W}_{3}}, \lambda_{2}=-1-\frac{1}{\sqrt{3}} \sqrt{\mathrm{W}_{3}}$

substituting the value of $\lambda_{1}$ in (6) we get

$$
\begin{gathered}
=1+\left[-1+\frac{\sqrt{\mathrm{W}_{3}}}{\sqrt{3}}\right]^{3}+3\left[-1+\frac{\sqrt{\mathrm{W}_{3}}}{\sqrt{3}}\right]^{2} \\
+3\left[-1+\frac{\sqrt{\mathrm{W}_{3}}}{\sqrt{3}}\right]-\left[1+\left[-1+\frac{\sqrt{\mathrm{W}_{3}}}{\sqrt{3}}\right]\right]\left(\mathrm{W}_{1}+\mathrm{W}_{2}\right)=0
\end{gathered}
$$

$\mathrm{W}_{3}\left(2 \mathrm{~W}_{2}+3 \mathrm{~W}_{3}\right)^{2}=27 \mathrm{~W}_{1}^{2}$
If $\mathrm{W}_{2}=\mathrm{W}_{3}$

$\Rightarrow 27 \mathrm{w}_{1}^{2}=25 \mathrm{w}_{\mathrm{a}}^{2}$

A necessary and sufficient condition for $f(\lambda)$ to have a pair of complex conjugate roots is the that $\mathrm{f}\left(\lambda_{1}\right) \mathrm{f}\left(\lambda_{2}\right)>0$, according Ruiz, Owens and Townley [1].From (5) we obtain

$\mathrm{f}\left(\lambda_{1}\right) \mathrm{f}\left(\lambda_{2}\right)=\left[1-\frac{W_{3}}{a}\right]>0$

$\Rightarrow \mathrm{W}_{3}<3$

Let

$$
\begin{aligned}
B & =\left[\begin{array}{lccr}
-1 & 1 & 0 & 0 \\
0 & -1 & 1 & 0 \\
0 & 0 & -1 & 1 \\
\mathrm{~W}_{1} & \mathrm{~W}_{2} & \mathrm{~W}_{3} & -1
\end{array}\right] \\
\mathrm{B} & =\left[\begin{array}{lllr}
-1 & 1 & \mathrm{C}_{2}=\mathrm{C}_{2}+\mathrm{C}_{3} & \\
0 & 0 & 0 & 0 \\
0 & -1 & 1 & 0 \\
\mathrm{~W}_{1} & \mathrm{~W}_{2}+\mathrm{W}_{3} & \mathrm{~W}_{3} & -1
\end{array}\right] \\
B & =\left[\begin{array}{lcr}
-1 & 1 & 0 \\
0 & -1 & 1 \\
\mathrm{~W}_{1} & \mathrm{~W}_{2}+\mathrm{W}_{3} & -1
\end{array}\right]
\end{aligned}
$$

The roots of the characteristic polynomial $B-\lambda I=0$ is define by

$$
(-1-\lambda)^{3}-(-1-\lambda)\left(\mathrm{W}_{2}+\mathrm{W}_{3}\right)+\mathrm{W}_{1}=0 .
$$

Let

$\emptyset_{(\lambda)}:=-\left[1+\lambda^{3}+3 \lambda^{2}+3 \lambda\right]+(1+\lambda)\left(\mathrm{W}_{2}+\mathrm{W}_{3}\right)+\mathrm{W}_{1}=0 .(10)$

Differentiating (10)

$\emptyset^{\prime}(\lambda)=3 \lambda^{2}+6 \lambda-\left(\mathrm{W}_{2}+\mathrm{W}_{3}-3\right)=0$.

The roots of (11) are given by

$\lambda_{a}=-1+\frac{1}{\sqrt{a}} \sqrt{W_{2}+W_{a}}, \lambda_{4}=-1-\frac{1}{\sqrt{a}} \sqrt{W_{2}+W_{a}}$,

substituting the value of $\lambda_{3}$ in (10) we get

$1+\left[-1+\frac{\sqrt{W_{2}+W_{a}}}{\sqrt{3}}\right]^{a}+3\left[-1+\frac{\sqrt{W_{2}+W_{a}}}{\sqrt{3}}\right]^{2}$ 
$+3\left[-1+\frac{\sqrt{W_{2}+W_{2}}}{\sqrt{3}}\right]-\left[1+\left[-1+\frac{\sqrt{W_{2}+W_{a}}}{\sqrt{3}}\right]\left(W_{2}+W_{2}\right)-W_{1}=0\right.$

$\left(\mathrm{W}_{2}+\mathrm{W}_{3}\right)-\mathrm{W}_{1}=0$

$4\left(\mathrm{~W}_{2}+\mathrm{W}_{3}\right)^{3}=27 \mathrm{~W}_{1}^{2}$

If $\mathrm{W}_{2}=\mathrm{W}_{3}$

$\Rightarrow 27 \mathrm{~W}_{1}^{2}=32 \mathrm{~W}_{2}^{3}$

From (10) we derive

$$
\begin{aligned}
& \emptyset_{\left(h_{1}\right)} \emptyset_{\left(h_{2}\right)}=\left\lceil 1-\frac{\left(W_{2}+W_{2}\right)}{2}\right\rceil>0 \\
\Rightarrow \quad & W_{2}+W_{3}<3 .
\end{aligned}
$$

Equation (9) and (14) put condition on $\mathrm{W}_{2}$ and $\mathrm{W}_{3}$ for the system of equations (1)-(4) to have a limit cycle at the origin.

\section{Section III}

Theorem $127 \mathrm{~W}_{1}^{2}=32 \mathrm{~W}_{2}{ }^{3}$ and $\mathrm{W}_{2}=\mathrm{W}_{3}=3, \mathrm{~W}_{1}= \pm 4 \sqrt{ } 2$ hold then the system(1)-(4) has a unique equilibrium point at the origin.

Proof:-We assume that $\mathrm{X}=\left(\mathrm{X}_{1}, \mathrm{X}_{2}, \mathrm{X}_{3}, \mathrm{X}_{4}\right)$ is an equilibrium points of (1)-(4).

$\mathrm{X}_{1}=\tanh \left(\mathrm{X}_{2}(\mathrm{t})\right)$

$\mathrm{X}_{2}=\tanh \left(\mathrm{X}_{\mathrm{a}}(\mathrm{t})\right)$

$\mathrm{X}_{\mathrm{a}}=\tanh \left(\mathrm{X}_{4}(\mathrm{t})\right)$

$\mathrm{x}_{4}=\mathrm{W}_{1} \tanh \left(\mathrm{X}_{1}(\mathrm{t})\right)+\mathrm{W}_{2} \tanh \left(\mathrm{X}_{2}(\mathrm{t})\right)+\mathrm{W}_{3} \tanh \left(\mathrm{x}_{\mathrm{a}}(\mathrm{t})\right)(18)$

With the $\mathrm{W}_{1}, \mathrm{~W}_{2}, \mathrm{~W}_{3} \in \mathrm{R}$ clearly, $\mathrm{X}=0$ satisfies(15) to (18) and is therefore and equilibrium points. Substituting the value of $\mathrm{X}_{1}, \mathrm{X}_{2}, \mathrm{X}_{3}$ from (15)-(18) in to (18) and $\mathrm{W}_{2}=\mathrm{W}_{3}$ we obtain.

$\mathrm{X}_{4}=\mathrm{W}_{1} \tanh _{4}\left(\mathrm{X}_{4}(\mathrm{t})\right)+\mathrm{W}_{2} \tanh _{3}\left(\mathrm{X}_{4}(\mathrm{t})\right)+\mathrm{W}_{2} \tanh _{2}\left(\mathrm{X}_{4}(\mathrm{t})\right)$ (19)

Since we take $(\xi)$ to denote the the $\mathrm{k}^{\text {th }}$ iterate of $\tanh (\xi)$ in the notation of Bo Gao and Weining Zhang [2], $\tanh _{\mathrm{k}}(\xi)=$ $\tanh (\tanh (\ldots . .(\tanh (\xi))))$. And $\tanh _{2}\left(\mathrm{X}_{4}\right)=\tanh \left(\tanh \left(\mathrm{X}_{4}\right)\right)$, similarly

we can derive $\tanh _{3}\left(\mathrm{X}_{4}\right)$ and $\tanh _{4}\left(\mathrm{X}_{4}\right)$.

Substituting $\mathrm{W}_{2}=\mathrm{W}_{3}=3, \mathrm{~W}_{1}=-4 \sqrt{ } 2$ in (19)

Let $\mathrm{f}\left(\mathrm{X}_{4}\right) \equiv-4 \sqrt{2} \tanh _{4}\left(\mathrm{X}_{4}(\mathrm{t})\right)+3 \tanh _{\mathrm{a}}\left(\mathrm{X}_{4}(\mathrm{t})\right)$

$+3 \tanh _{2}\left(\mathrm{X}_{4}(\mathrm{t})\right)-\mathrm{X}_{4}=0$

$\mathrm{f}\left(\mathrm{X}_{4}\right)<0$ and $\mathrm{f}\left(\mathrm{X}_{4}\right)>0$ for all value of $\mathrm{X}_{4}>0$ and $\mathrm{X}_{4}<0$ respectively.

Substituting $\mathrm{W}_{2}=\mathrm{W}_{3}=3, \mathrm{~W}_{1}=4 \sqrt{ } 2$ in (19)

Let $\mathrm{f}\left(\mathrm{X}_{4}\right) \equiv 4 \sqrt{2} \tanh _{4}\left(\mathrm{X}_{4}(\mathrm{t})\right)+3 \tanh _{\mathrm{a}}\left(\mathrm{X}_{4}(\mathrm{t})\right)$

$+3 \tanh _{2}\left(\mathrm{X}_{4}(\mathrm{t})\right)-\mathrm{X}_{4}=0$
$\mathrm{f}\left(\mathrm{X}_{4}\right)>0$ and $\mathrm{f}\left(\mathrm{X}_{4}\right)<0$ for all value of $\mathrm{X}_{4}>0$ and $\mathrm{X}_{4}<0$ respectively.

The function $\mathrm{f}\left(\mathrm{X}_{4}\right)$ either monotonically increases or decreases for all values of $\mathrm{X}_{4}$ therefore the system (15)-(18) has a unique equilibrium point at the origin.

Theorem 2 If $27 \mathrm{~W}_{1}{ }^{2}=25 \mathrm{~W}_{2}{ }^{3}$ and $\mathrm{W}_{2}=\mathrm{W}_{3}=3, \mathrm{~W}_{1}= \pm 5$ then the system(1)-(4) has a unique equilibrium point at the origin.

Proof:- In the previous theorem with similar analysis we examine equation (19)with the given condition substituting $\mathrm{W}_{2}=$ $\mathrm{W}_{3}=3, \mathrm{~W}_{1}=5$ in (19)

Let

$\mathrm{f}\left(\mathrm{X}_{4}\right) \equiv 5 \tanh _{4}\left(\mathrm{X}_{4}(\mathrm{t})\right)+3 \tanh _{\mathrm{a}}\left(\mathrm{X}_{4}(\mathrm{t})\right)+3 \tanh _{2}\left(\mathrm{X}_{4}(\mathrm{t})\right)$

$-\mathrm{X}_{4}=0$

$f\left(X_{4}\right)>0$ and $f\left(X_{4}\right)<0$ for all value of $X_{4}>0$ and $X_{4}<0$ respectively.

Substituting $\mathrm{W}_{2}=\mathrm{W}_{3}=3, \mathrm{~W}_{1}=-5$ then

Let

$\mathrm{f}\left(\mathrm{X}_{4}\right) \equiv-5 \tanh _{4}\left(\mathrm{X}_{4}(\mathrm{t})\right)+3 \tanh _{\mathrm{g}}\left(\mathrm{X}_{4}(\mathrm{t})\right)+3 \tanh _{2}\left(\mathrm{X}_{4}(\mathrm{t})\right)$

$-\mathrm{X}_{4}=0$

$\mathrm{f}\left(\mathrm{X}_{4}\right)>0$ or $\mathrm{f}\left(\mathrm{X}_{4}\right)<0$ if $\mathrm{X}_{4}<1.1375$ or $\mathrm{X}_{4}>1.1375$

respectively. and $f\left(X_{4}\right)=0$ if $X_{4}=1.1375$

The function $\mathrm{f}\left(\mathrm{X}_{4}\right)$ either monotonically increases or decreases for all values of $X_{4}$ therefore the system (15)-(18) has a unique equilibrium point at the origin.

The equilibrium for all $\mathrm{W}_{1}, \mathrm{~W}_{2}, \mathrm{~W}_{3} \in \mathrm{R}$ Substituting the first three equation of (4) into the fourth one we obtain $\Psi_{W_{2} W_{2} W_{2}}(\xi)=0$ where Equation (4) can be reduced in term of $\mathrm{X}_{4}$ only by substituting the value of $\mathrm{X}_{1}, \mathrm{X}_{2}, \mathrm{X}_{3}$ for (1)-(3). Let $\mathrm{X}_{4}=\xi$ be equilibrium point of (4) and we obtain

$\Psi_{W_{2}} W_{2} W_{2}(\xi):=-\xi+W_{1} \operatorname{taanh}_{4}\left(X_{4}(\xi)\right)+W_{2} \operatorname{taanh}_{a}\left(X_{4}(\xi)\right)$

$+\mathrm{W}_{3} \operatorname{taanh}_{2}\left(\mathrm{X}_{4}(\xi)\right)$

In the next for the our work is based on the method used by Bo Gao and Weining Zhang [2], in determining the zero of a polynomial respectively three node of recurrent neural network. Here we discussing four node recurrent neural network.

Lemma ; $\Psi_{W_{2} W_{2} W_{2}}(\xi)$ has at most two positive zeros for all $\mathrm{W}_{1}, \mathrm{~W}_{2}, \mathrm{~W}_{3} \in \mathrm{R}$.

Proof. Consider the second order derivative

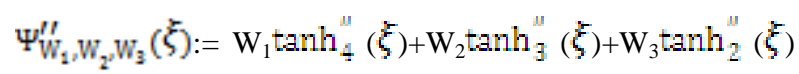

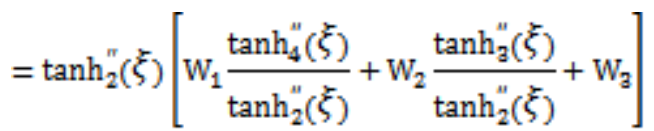


Where $\tanh _{2}^{\mathbb{E}}(\xi)$ and $\tanh _{\text {g }}^{\mathbb{E}}(\xi)$ are both negative for $(\xi)>$ 0 . So that

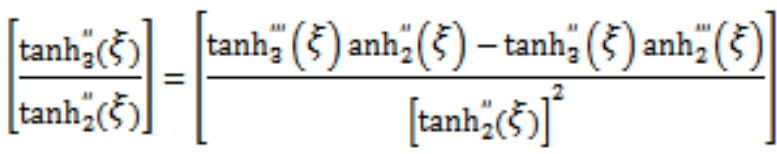

$$
\begin{aligned}
& <\frac{\operatorname{sech}^{2}(\xi) \tanh _{a}^{\gamma}(\xi) \Omega 1(\xi)}{\left[\tanh (\xi)+\operatorname{sech}^{2}(\xi) \tanh _{2}(\xi)\right]^{2}}
\end{aligned}
$$

Bo Gao and Weining Zhang [2]

$$
\begin{aligned}
& \Omega_{1}(\xi):=\left[\tanh (\xi) \operatorname{sech}^{2}(\tanh (\xi)) \operatorname{sech}^{2}\left(\tanh _{2}(\xi)\right)-\right. \\
& \left.\tanh _{a}(\xi)\right]+\tanh 2(\xi)\left[\tanh _{2}(\xi) \operatorname{sech}^{2}\left(\tanh _{2}(\xi)\right)-\tanh _{a}(\xi)\right]
\end{aligned}
$$

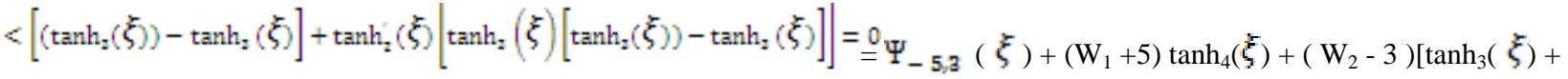

$$
\begin{aligned}
& \left.\tanh _{2}(\xi)\right]<0
\end{aligned}
$$

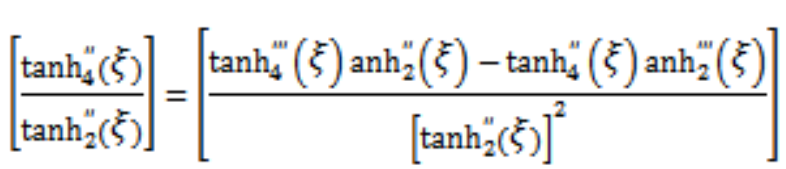$$
<\frac{\operatorname{sech}^{2}(\xi) \tanh _{4}{ }^{\prime}(\xi) \Omega 2(\xi)}{\left[\tanh (\xi)+\operatorname{sech}^{2}(\xi) \tanh _{2}(\xi)\right]^{2}}
$$$$
\Omega_{2}(\xi):=\left[\begin{array}{c}
\tanh (\xi) \operatorname{sech}^{2}(\tanh (\xi)) \operatorname{sech}^{2}\left(\tanh _{2}(\xi)\right) \operatorname{sech}^{2} \\
\left(\tanh _{2}(\xi)\right)-\tanh _{4}(\xi)
\end{array}\right]
$$$$
+\tanh _{2}(\xi)\left[\tanh _{a}(\xi) \operatorname{sech}^{2}\left(\tanh _{a}(\xi)\right)-\tanh _{4}(\xi)\right]
$$$$
\left.<\left[\left(\tanh _{4}(\xi)\right)-\tanh _{4}(\xi)\right]+\tanh _{2}(\xi)\left[\tanh _{4}(\xi)\right)-\tanh _{4}(\xi)\right]=\text { proof : From equation(24) }
$$

In this sub case that $\mathrm{W}_{1} \leq 5, \mathrm{~W}_{2}=\mathrm{W}_{3} \leq 3$ and

$\Psi_{5, a}(\xi)=\Psi_{5, a}(\xi)+\left(\mathrm{W}_{1}-5\right) \tanh _{4}(\xi)+\left(\mathrm{W}_{2}-3\right.$

)$\left[\tanh _{3}(\xi)+\tanh _{2}(\xi)\right]$

This proves that $\Psi_{ \pm_{5} \text { a }}$ has no positive zero.

Theorem4- In this case $27 \mathrm{~W}_{1}{ }^{2}=32 \mathrm{~W}_{2}{ }^{3}$ and $\mathrm{W}_{2}=\mathrm{W}_{3} \leq 3$ and $\mathrm{W}_{1} \leq \pm 4 \sqrt{ } 2,{ }^{\Psi_{ \pm 4 \sqrt{2} \mathrm{a} a}}<0$ for all $\xi>0$ Therefore ${ }^{\Psi_{ \pm 4 \sqrt{2_{x} \mathrm{a}}}}$ has positive zero

$$
\Psi_{ \pm 4 \sqrt{2} x^{a}}(0)=(0)
$$

It shows that $\tanh _{a}^{m}(\xi) / \tanh _{2}^{m}(\xi)$ is a strictly decreasing in $\xi$ $>0$, and therefore,

$$
\left[\mathrm{W}_{1} \frac{\tanh _{4}^{\mathrm{I}}(\xi)}{\tanh _{2}{ }^{\mathrm{I}}(\xi)}+\mathrm{W}_{2} \frac{\tanh _{\mathrm{a}}{ }^{\mathrm{W}}(\xi)}{\tanh _{2}{ }^{\mathrm{I}}(\xi)}+\mathrm{W}_{3}\right]
$$

has at most a positive zero.

In the view of (25) it implies $\Psi_{W_{12} W_{2} W_{3}}^{n}(\xi)$ also has a positive also has zero here the function $\Psi_{W_{2}} W_{z} W_{z}(\xi)$ has at most two positive zero by Rolle's Theorem.

Theorem 3- In this case $27 \mathrm{~W}_{1}{ }^{2}=25 \mathrm{~W}_{2}{ }^{3}$ and $\mathrm{W}_{2}=\mathrm{W}_{3} \leq 3$ and $\mathrm{W}_{1} \leq \pm 5$ then ${ }^{\Psi_{ \pm 5_{x} a} a}<0$ for all $\xi>0$. Therefore $\Psi_{\Psi_{5_{a} a} a}$ has positive zero since $\Psi_{ \pm 5 ; a}(0)=(0)$
$\Psi_{-4 \sqrt{2} z_{a} a}(\xi)=-1-4 \sqrt{ } 2 \operatorname{sech}^{2}{ }_{4}(\xi) \operatorname{sech}_{3}^{2}(\xi) \operatorname{sech}_{2}^{2}(\xi) \operatorname{sech}^{2}(\xi)$ $+3 \operatorname{sech}_{3}^{2}(\xi) \operatorname{sech}_{2}^{2} \operatorname{sech}^{2}(\xi)+3 \operatorname{sech}^{2}{ }_{2}(\xi) \operatorname{sech}^{2}(\xi)$

$=-1+\operatorname{sech}_{2}{ }_{2}(\xi) \operatorname{sech}^{2}(\xi)\left[-4 \sqrt{ } 2 \operatorname{sech}_{4}{ }_{4}(\xi) \operatorname{sech}_{3}{ }_{3}(\xi)+3\right.$ $\left.\operatorname{sech}_{3}^{2}(\xi)+3\right]$

$<-1+\operatorname{sech}_{2}^{2}(\xi) \operatorname{sech}^{2}(\xi)\left[\left(1-\tanh _{3}{ }^{2}(\xi)\right)\left\{-4 \sqrt{ } 2 \operatorname{sech}_{4}^{2}(\xi)\right.\right.$ $+3\}+3]<0$

$<-1+\left[1-\tanh _{2}^{2}(\xi)\right]\left[1-\tanh ^{2}(\xi)\right]\left[\left(1+\tanh _{3}^{2}(\xi)\right)\right.$

$\left.\left\{(3-4 \sqrt{ } 2)+4 \sqrt{ } 2 \tanh ^{2}{ }_{4}(\xi)\right\}+3\right]<0$

By lemma 2.1 Bo Gao and Weining Zhang [2]. $\xi>0$

$\Psi_{-4 \sqrt{2} x^{a}}(\xi)=\Psi_{-4 \sqrt{2} x^{a}}(\xi)+\left(\mathrm{W}_{1}+4 \sqrt{ } 2\right) \tanh _{4}(\xi)+\left(\mathrm{W}_{2}-\right.$ 3) $\tanh _{3}(\xi)+\left(\mathrm{W}_{2}-3\right) \tanh _{2}(\xi)<0$

proof :- From equation(24) 


$$
\begin{aligned}
& =\Psi_{-4 \sqrt{2} a^{a}}(\xi)+\left(\mathrm{W}_{1}+4 \sqrt{ } 2\right) \tanh _{4}(\xi)+\left(\mathrm{W}_{2}-3\right)\left[\tanh _{3}(\xi)\right. \\
& \left.+\tanh _{2}(\xi)\right]<0
\end{aligned}
$$

In this sub case that $\mathrm{W}_{1} \leq 4 \sqrt{ } 2, \mathrm{~W}_{2}=\mathrm{W}_{3} \leq 3$ and

$\Psi_{4 \sqrt{2} a \mathrm{a}}(\xi)=\Psi_{4 \sqrt{2}, \mathrm{a}}(\xi)+\left(\mathrm{W}_{1}-4 \sqrt{ } 2\right) \tanh _{4}(\xi)+\left(\mathrm{W}_{2}-\right.$

3) $\left[\tanh _{3}(\xi)+\tanh _{2}(\xi)\right]<0$

This proves that ${ }^{\Psi_{ \pm 4 \sqrt{2} x_{x} \mathrm{a}}}$ ( $\xi$ ) has no positive zero.

\section{TRAINING OF THE MODEL}

The learning competence of recurrent neural network define by the equation (1)-(4), with the initial time at $t=t_{0}$, here a periodic signal sint is fed as input to the network. From initial time $\mathrm{t}_{0}=0.0 \mathrm{sec}$ up to a time $\mathrm{t}=1.8 \mathrm{sec}$, the network (1) to (4) modify its parameters $\mathrm{W}_{1}, \mathrm{~W}_{2}$ and $\mathrm{W}_{3}$. Once the network is trained the output $\tanh \mathrm{X}_{4}(\mathrm{t})$ is fed back so as to replace the initial period signal sint.

Further consider the recurrent neural network described by the system

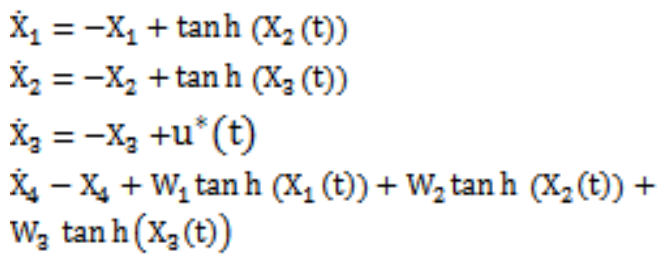

$$
\mathrm{Y}(\mathrm{t})=\tan \mathrm{h}\left(\mathrm{X}_{4}(\mathrm{t})\right),
$$

with $X(t) \in R^{3}, X(0) \neq 0$ and $U(t)$ is given by

$$
\mathrm{U}^{*}(\mathrm{t})=\left\{\begin{array}{lr}
\mathrm{U}(\mathrm{t})=\sin (\mathrm{t}) & 0 \leq \mathrm{t}<\mathrm{t}_{0} \\
\mathrm{Y}(\mathrm{t})=\tanh \left(\mathrm{X}_{4}(\mathrm{t})\right) & \mathrm{t}_{0} \leq 0 .
\end{array}\right.
$$

when $\mathrm{t}_{0}=1.8 \mathrm{sec}$, the weight $\mathrm{W}_{1}, \mathrm{~W}_{2}$ and $\mathrm{W}_{3}$ are updated by minimizing by energy function

$$
E(t)=1 / 2[y(t)-u(t)]^{2},
$$

such a gradient descent approach is used by Ruiz, Owens and Townley [1] they described the equation

$$
\begin{aligned}
& \left(\partial \mathrm{E} / \partial \mathrm{W}_{1}\right)=(\mathrm{y}-\mathrm{u})\left[\left(1-\tanh ^{2}\left(\mathrm{X}_{3}(\mathrm{t})\right)-(\cos t)\right] \Delta_{\mathrm{d}} \tanh ^{2}\left(\mathrm{X}_{1}(\mathrm{t})\right)\right. \\
& \left(\partial \mathrm{E} / \partial \mathrm{W}_{2}\right)=(\mathrm{y}-\mathrm{u})\left[\left(1-\tanh ^{2}\left(\mathrm{X}_{3}(\mathrm{t})\right)-(\cos t)\right] \Delta_{\mathrm{d}} \tanh ^{2}\left(\mathrm{X}_{2}(\mathrm{t})\right)\right. \\
& \left(\partial \mathrm{E} / \partial \mathrm{W}_{3}\right)=(\mathrm{y}-\mathrm{u})\left[\left(1-\tanh ^{2}\left(\mathrm{X}_{3}(\mathrm{t})\right)-(\cos \mathrm{t})\right] \Delta_{\mathrm{d}} \tanh ^{2}\left(\mathrm{X}_{3}(\mathrm{t})\right)\right.
\end{aligned}
$$

The differential operator $\Delta_{\mathrm{d}}:=(1+\mathrm{d} / \mathrm{dt})^{-1}$ with the auxiliary variables $\mathrm{V}_{1}, \mathrm{~V}_{2}$ and $\mathrm{V}_{3}$ is defined as
$\mathrm{V}_{1}:=\left(\partial \mathrm{E} / \partial \mathrm{W}_{1}\right), \mathrm{V}_{2}:=\left(\partial \mathrm{E} / \partial \mathrm{W}_{2}\right), \mathrm{V}_{3}:=\left(\partial \mathrm{E} / \partial \mathrm{W}_{3}\right)$, we then have

$$
\begin{aligned}
& \dot{\mathrm{V}}_{1}=-\mathrm{V}_{1}+\tanh \left(\mathrm{X}_{1}(\mathrm{t})\right) \\
& \dot{\mathrm{V}}_{2}=-\mathrm{V}_{2}+\tanh \left(\mathrm{X}_{2}(\mathrm{t})\right) \\
& \dot{\mathrm{V}}_{3}=-\mathrm{V}_{2}+\tanh \left(\mathrm{X}_{3}(\mathrm{t})\right),
\end{aligned}
$$

and updates the rules for $\mathrm{W}_{1}, \mathrm{~W}_{2}, \mathrm{~W}_{3}$ (Ruiz, Owens and Townley, [1]).

$$
\begin{aligned}
& \dot{W}_{1}=\eta\left(\partial \mathrm{E} / \partial \mathrm{W}_{1}\right)=\eta(\mathrm{y}-\mathrm{u})\left[\left(1-\tanh ^{2}\left(\mathrm{X}_{3}(\mathrm{t})\right)-(\cos t)\right] \mathrm{V}_{1} \quad \eta>0\right. \\
& \dot{W}_{2}=\eta\left(\partial \mathrm{E} / \partial \mathrm{W}_{2}\right)=\eta(\mathrm{y}-\mathrm{u})\left[\left(1-\tanh ^{2}\left(\mathrm{X}_{3}(\mathrm{t})\right)-(\operatorname{cost})\right] \mathrm{V}_{2}\right. \\
& \dot{W}_{3}=\eta\left(\partial \mathrm{E} / \partial \mathrm{W}_{3}\right)=\eta(\mathrm{y}-\mathrm{u})\left[\left(1-\tanh ^{2}\left(\mathrm{X}_{3}(\mathrm{t})\right)-(\operatorname{cost})\right] \mathrm{V}_{3}\right.
\end{aligned}
$$

with $\mathrm{W}(0)=\left(\mathrm{W}_{1} \mathrm{~W}_{2} \mathrm{~W}_{3}\right)^{\prime}(0)=: \mathrm{W}_{0}, \mathrm{~V}(0)=\left(\mathrm{V}_{1} \mathrm{~V}_{2} \mathrm{~V}_{3}\right)^{\prime}(0)=$ : $\mathrm{V}_{0}$ arbitrary.

\section{CONCLUSION}

In the foregoing sections we have investigated the zeros of the system of four node recurrent neural network. In section (i) we find that the origin is the only unique equilibrium point subject to the some condition on weights W1,W2,W3. In section (ii) we explore the possibility of more than one zero of the equations and in the theorem (2.1) Bo Gao and Weining Zhang [2], we prove it. In section (iii) we further analyzed the weights $\mathrm{W} 1$, W2, W3. In section (iv) described the training and learning capabilities of the network. We have shown that the model can be learn to train the described periodic function with the maximum time spend of 1.8 seconds.

\section{REFERENCES}

[1] A. Ruiz, D.H. Owens, and S. Townley, "Existence, learning, and replication of periodic motions in recurrent neural network," IEEE Trans. Neural Network. Vol. 9. no 4, pp 651- 661, jul.1998.

[2] Bo. Gao, and Weinian. Zhang, "Equilibria and their bifurcation in a recurrent neural network involving iterates of a transcendental function," IEEE Trans. Neural Networks. Vol. 19 No. 5. Pp.782-794, May 2008.

[3] D. Marr. and T. Poggio. Cooperative computation of stereo disparity, sci., vol 194 pp 283 -287, 1976.

[4] J.K. Hale, Theory of function differential equations $2^{\text {nd }}$ ed. Applied mathematical sciences, vol. 3 Springer, new York, 1977.

[5] J.J. Hofield, Neurons with graded response have collective computational properties like those of two state neurons proceeding of the national academy of sciences of the United States of America 81 (1984) no .10 3088- 3092.

[6] J.L. McClelland. D. E. Rumclhart. and G.E. Hinton. "The appeal of parallel distributed processing." in Rinehart. D.E., McClelland. J.L., and the PDP research group Eds., parallel distributed processing explorations in microstructure of 
cognition volume 1. Foundations Cambridge MA:MIT Press 1986 .

[7] S. Hasting, J. Tyson, and D. Webster, "Existence of periodic solution for negative feedback cellular control system,” J.Differential Equations, vol.25, pp.39-64,1977.

[8] R. Szeliski. "cooperative algorithms for solving random dot stereo grams", Carnegie Mellon Univ. Tech Rep CMU-CS $-86-133,1986$.
[9] Yingguo Li "Stability and Bifurcation Analysis of a ThreeDimensional Recurrent Neural Network with Time Delay" Hindawi Publishing Corporation Journal of Applied Mathematics. Volume 2012 Article ID 357382, 13 pages doi:10.1155/2012/357382

[10] Yujiao Huang, Huaguang Zhang, Zhanshan Wang and Mo Zhao. "Stability Analysis of Multiple Equilibria for Recurrent Neural Networks," Advances in neural networkISNN 2012. Lecture notes in computer science Volume 7367, 2012, pp196-205. 


\section{APPENDIX}

March of $\eta=.25, X_{1}, X_{2}, X_{3}, X_{4}, V_{1}, V_{2}, V_{3}, \dot{W}_{1}, \dot{W}_{2}$ and $\dot{W}_{3}$ in the initial time $(\mathrm{t}=0.0-1.8 \mathrm{sec})$ with the initial weight $\mathrm{W}_{1}=0.25$ and condition, $27 \mathrm{~W}_{1}^{2}=25 \mathrm{~W}_{2}^{3}$ From (7)

\begin{tabular}{|l|c|c|c|c|c|c|}
\hline $\mathrm{t}$ & $\mathrm{X}_{1}(\mathrm{t})$ & $\mathrm{X}_{2}(\mathrm{t})$ & $\mathrm{X}_{3}(\mathrm{t})$ & $\mathrm{X}_{4}(\mathrm{t})$ & $\mathrm{V}_{1}$ & $\mathrm{~V}_{2}$ \\
\hline 0.2 & -1.1347 & -1.2195 & -0.8187 & -.7267 & -1.1522 & -1.1347 \\
0.4 & -1.1300 & -1.2426 & -0.6703 & -.7314 & -1.1532 & -1.1300 \\
0.6 & -1.1286 & -1.2499 & -0.5488 & -.7330 & -1.1535 & -1.2686 \\
0.8 & -1.1299 & -1.2437 & -0.4493 & -.7317 & -1.1532 & -1.2299 \\
1.0 & -1.1329 & -1.2280 & -0.3678 & -.7285 & -1.1526 & -1.1329 \\
1.2 & -1.1372 & -1.2068 & -0.3012 & -.7241 & -1.1516 & -1.1372 \\
1.4 & -1.1420 & -1.1832 & -0.2465 & -.7193 & -1.1506 & -1.1420 \\
1.6 & -1.1469 & -1.1595 & -0.2019 & -.7145 & -1.1496 & -1.1469 \\
1.8 & -1.1517 & -1.1369 & -0.1653 & -.7099 & -1.1486 & -1.1517 \\
\hline
\end{tabular}

\begin{tabular}{|c|c|c|c|}
\hline $\mathrm{V}_{3}$ & $\dot{W}_{1}$ & $\dot{W}_{2}$ & $\dot{W}_{3}$ \\
\hline-1.2195 & 0.0960 & 0.0964 & 0.1017 \\
-12426 & 0.1402 & 0.1374 & 0.1511 \\
-1.2499 & 0.2094 & 0.2042 & 0.2261 \\
-1.2437 & 0.3169 & 0.3105 & 0.3417 \\
-1.2280 & 0.4816 & 0.4734 & 0.5131 \\
-1.2068 & 0.7319 & 0.7228 & 0.7670 \\
-1.1832 & 1.1099 & 1.1016 & 1.1413 \\
-1.1595 & 1.6782 & 1.6743 & 1.6927 \\
-1.1369 & 2.5301 & 2.5370 & 2.5044 \\
\hline
\end{tabular}

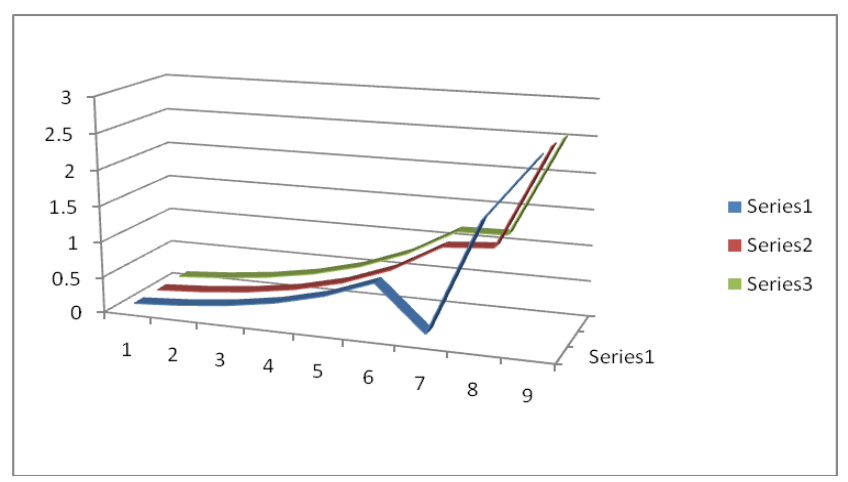

Where series 1 ,series2, series 3 denotes $\dot{W}_{1}, \dot{W}_{2}, \dot{W}_{3}$ respectively
March of $\eta=.25, X_{1}, X_{2}, X_{3}, X_{4}, V_{1}, V_{2}, V_{3}, \dot{W}_{1}, \dot{W}_{2}$ and $\mathrm{W}_{3}$ in the initial time $(\mathrm{t}=0.0-1.8 \mathrm{sec})$ with the initial weight $\mathrm{W}_{1}=0.25$ and condition, $27 \mathrm{~W}_{1}{ }^{2}=32 \mathrm{~W}_{2}{ }^{3}$ From (12)

\begin{tabular}{|l|l|l|r|r|r|r|}
\hline $\mathrm{t}$ & $\mathrm{X}_{1}(\mathrm{t})$ & $\mathrm{X}_{2}(\mathrm{t})$ & $\mathrm{X}_{3}(\mathrm{t})$ & $\mathrm{X}_{4}(\mathrm{t})$ & $\mathrm{V}_{1}$ & $\mathrm{~V}_{2}$ \\
\hline 0.2 & -1.1347 & -1.2195 & -0.8187 & -.7440 & -1.1522 & -1.1347 \\
0.4 & -1.1300 & -1.2426 & -0.6703 & -.7487 & -1.1532 & -1.1300 \\
0.6 & -1.1286 & -1.2499 & -0.5488 & -.7503 & -1.1535 & -1.2686 \\
0.8 & -1.1299 & -1.2437 & -0.4493 & -.7490 & -1.1532 & -1.2299 \\
1.0 & -1.1329 & -1.2280 & -0.3678 & -.7458 & -1.1526 & -1.1329 \\
1.2 & -1.1372 & -1.2068 & -0.3012 & -.7414 & -1.1516 & -1.1372 \\
1.4 & -1.1420 & -1.1832 & -0.2465 & -.7366 & -1.1506 & -1.1420 \\
1.6 & -1.1469 & -1.1595 & -0.2019 & -.7317 & -1.1496 & -1.1469 \\
1.8 & -1.1517 & -1.1369 & -0.1653 & -.7271 & -1.1486 & -1.1517 \\
\hline
\end{tabular}

\begin{tabular}{|c|c|c|c|}
\hline $\mathrm{V}_{3}$ & $\dot{\mathrm{W}}_{1}$ & $\dot{\mathrm{W}}_{2}$ & $\dot{\mathrm{W}}_{3}$ \\
\hline-1.2195 & 0.1004 & 0.0989 & 0.1063 \\
-1.2426 & 0.1456 & 0.1427 & 0.1569 \\
-1.2499 & 0.2160 & 0.2113 & 0.2340 \\
-1.2437 & 0.3248 & 0.3182 & 0.3503 \\
-1.2280 & 0.4913 & 0.4829 & 0.5234 \\
-1.2068 & 0.7436 & 0.7343 & 0.7792 \\
-1.1832 & 1.1242 & 1.1158 & 1.1560 \\
-1.1595 & 1.6956 & 1.6916 & 1.7102 \\
-1.1369 & 2.5511 & 2.5580 & 2.5251 \\
\hline
\end{tabular}

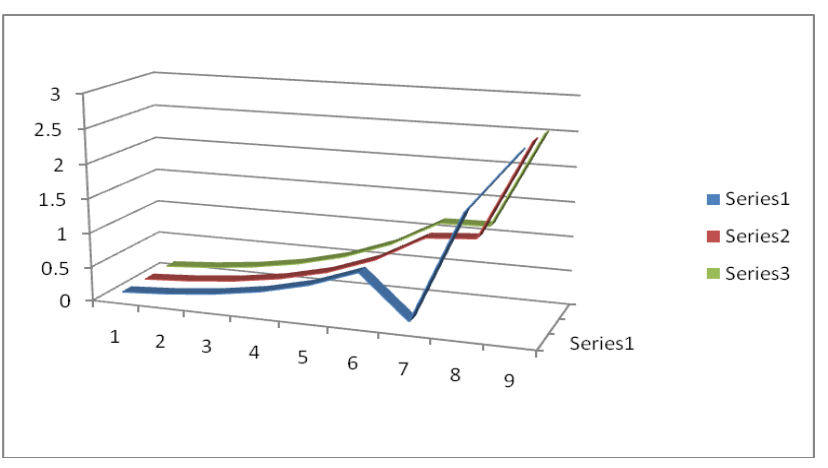

Where series1,series2, series3 denotes $\dot{W}_{1}, \dot{W}_{2}, \dot{W}_{3}$ respectively. 